\title{
PEMBAGIAN POSTER PENCEGAHAN PENYAKIT DIABETES MELLITUS DI KELURAHAN BENDA BARU RW 01 TANGERANG SELATAN
}

\section{POSTER PREVENTION OF DIABETES MELLITUS DISTRIBUTION IN KELURAHAN BENDA BARU RW 01 SOUTH TANGERANG}

\author{
${ }^{1)}$ Munaya Fauziah, ${ }^{1)}$ Siti Riptifah Tri Handari, ${ }^{2)}$ Ega Wiyasih, ${ }^{2)}$ Dinda Demayah \\ ${ }^{1)}$ Dosen Program Studi Kesehatan Masyarakat Universitas Muhammadiyah Jakarta \\ ${ }^{2)}$ Mahasiswa Program Studi Kesehatan Masyarakat Universitas Muhammadiyah Jakarta \\ Alamat: Jl. K.H. Ahmad Dahlan, Cireundeu, Ciputat, Tangerang Selatan \\ *Email: munaya.fauziah@umj.ac.id
}

\begin{abstract}
ABSTRAK
Diabetes mellitus merupakan penyebab kematian di negara maju dan menjadi epidemi di negaranegara berkembang. Program penanggulangan penyakit tidak menular telah dilakukan oleh Puskesmas Benda Baru, Kelurahan Benda Baru melalui program di Posbindu, namun promosi kesehatan mengenai penyakit tidak menular juga diperlukan di Posyandu. Pengabdian masyarakat ini dilakukan untuk meningkatkan pengetahuan masyarakat terutama ibu-ibu pengunjung Posyandu RW 01 mengenai diabetes mellitus dengan teknik infografis yang menarik yaitu poster yang dibagikan dan penyuluhan kesehatan pencegahan diabetes mellitus. Metode yaitu ceramah yang dilaksanakan pada tanggal 17 Februari 2020. Evaluasi kegiatan dengan pretest dan post test sebelum pembagian poster dan penyuluhan. Hasil menunjukan adanya peningkatan pengetahuan yang bermakna mengenai diabetes mellitus pada ibu-ibu pengunjung posyandu. Saran kepada pengelola posyandu agar rutin memberikan promosi kesehatan mengenai penyakit tidak menular khususnya diabetes mellitus.
\end{abstract}

Kata kunci: penyuluhan, poster, pencegahan, diabetes mellitus

\begin{abstract}
Diabetes mellitus is a cause of death in developed countries and an epidemic in developing countries. Non-communicable disease prevention programs have been carried out by Benda Baru community health center, Benda Baru Village, through programs in Posbindu, but health promotion regarding non-communicable diseases is also needed at Posyandu. This community service is carried out to increase public knowledge, especially women who visit Posyandu RW 01 about diabetes mellitus with an interesting info graphic technique, the poster that is distributed and health counseling to prevent diabetes mellitus. The method used is counseling which was held on February 17, 2020. The evaluation of the activities conducted with a pretest and post test before and after the distribution of posters and counseling. The results showed that there was a significant increase in knowledge about diabetes mellitus in mothers who visit the posyandu. Suggestions for posyandu managers to routinely provide health promotion regarding non-communicable diseases, especially diabetes mellitus.
\end{abstract}

Keyword: counseling, poster, prevention, diabetes mellitus 
AS-SYIFA: Jurnal Pengabdian dan Pemberdayaan Kesehatan Masyarakat

\section{PENDAHULUAN}

Diabetes mellitus merupakan penyebab kematian di negara maju dan menjadi epidemik di banyak negara berkembang (Mahant SD, Kolay SK 2014, IDF 2017). Diabetes Mellitus Tipe II merupakan diabetes yang paling sering terjadi yaitu 90-95\% dari semua jenis diabetes mellitus (Wu Y, Ding Y, Tanaka Y, Zhang W, 2014). Pusdatin melaporkan ada kenaikan prevalensi diabetes mellitus di Indonesia (Kemenkes RI, 2019). Prevalensi DM berdasarkan diagnosis dokter pada penduduk umur $\geq 15$ tahun dalam hasil Riskesdas 2018 meningkat menjadi 2\% dibandingkan tahun 2013 (Kemenkes RI, 2019). Diabetes mellitus dan komplikasinya meningkatkan pengeluaran rumah tangga untuk pengobatan dan perawatan kesehatan.

Penyakit diabetes mellitus termasuk penyakit yang menjadi masalah kesehatan di Kelurahan Benda Baru. Survey pendahuluan menunjukkan adanya penderita penyakit diabetes mellitus di RW 01 sebanyak tiga orang. Pengabdian masyarakat yang menggunakan pendekatan media infografis (poster) terkait diabetes mellitus belum pernah dilakukan. Oleh karena itu dilakukan pengabdian masyarakat dosen Fakultas Kesehatan Masyarakat Universitas Muhammadiyah Jakarta yang melibatkan mahasiswa mengenai diabetes mellitus ini. Pengabdian masyarakat ini meliputi kegiatan dengan pembagian poster dan penyuluhan kesehatan pencegahan penyakit diabetes mellitus di RW 01 Kelurahan Benda Baru Pamulang Tangerang Selatan Tahun 2020.

\section{METODE}

Pengabdian masyarakat ini dilakukan dalam bentuk pembagian poster pencegahan diabetes mellitus dan penyuluhan kesehatan tentang pencegahan diabetes mellitus pada peserta posyandu di RW 01 Kelurahan Benda Baru. Kegiatan ini dilakukaan pada tanggal 17 Februari 2020. Mitra pengabdian masyarakat ini adalah Posyandu RW 01 Kelurahan Benda Baru. Pelaksanaan pengabdian masyarakat ini melibatkan mahasiswa Fakultas Kesehatan Masyarakat Universitas Muhammadiyah Jakarta. Peran mahasiswa yaitu membuat tampilan poster dan mendukung pelaksanaan kegiatan pengabdian masyarakat di posyandu. Peserta Posyandu terdiri dari 25 ibu-ibu. Ibu diberikan pre test mengenai diabetes mellitus dan diberikan poster pencegahan diabetes mellitus serta penyuluhan. Setelah itu dilakukan pengukuran tingkat pengetahuan dengan kuesioner post test terkait diabetes mellitus dan pencegahannya. Perbedaan tingkat pengetahuan sebelum dan sesudah pembagian poster dan penyuluhan dianalisis dengan uji $\mathrm{T}$.

\section{HASIL DAN PEMBAHASAN}

Kelurahan Benda Baru terdapat di Kecamatan Benda Baru Kota Tangerang Selatan, Banten. Penyuluhan dan pembagian poster pencegahan diabetes mellitus di daerah ini merupakan kegiatan pengabdian masyarakat dari Fakultas Kesehatan Masyarakat Universitas Muhammadiyah Jakarta. Kegiatan ini bertujuan untuk memberikan peningkatan pengetahuan masyarakat Kelurahan Benda Baru mengenai diabetes mellitus dan pencegahannya.

Dari hasil kegiatan pengabdian massyarakat ini didapatkan hasil sebagai berikut. Berikut

Tabel 1. Hasil Uji T Peningkatan Tingkat Pengetahuan Sebelum dan Sesudah Penyuluhan dan Pembagian Poster Pencegahan Diabetes Melitus di Kelurahan Benda Baru

\begin{tabular}{llll}
\hline Tingkat Pengetahuan & Rata-Rata & SD & Nilai P \\
\hline Pre test & 36.00 & 18.2 & 0.0001 \\
\hline Post test & 76.00 & 10.8 & \\
\hline
\end{tabular}

Sumber: Data primer, 2020 
Hasil menunjukkan adanya peningkatan pengetahuan mengenai definisi, faktor risiko, gejala, cara diagnosis dan cara pencegahan diabetes mellitus sebelum pembagian poster dan penyuluhan serta sesudahnya $(\mathrm{p}=0,0001)$.

Gambar 1. Kegiatan Pembagian Poster Pencegahan Penyakit Diabetes Mellitus Di Posyandu RW 01 Kelurahan Benda Baru

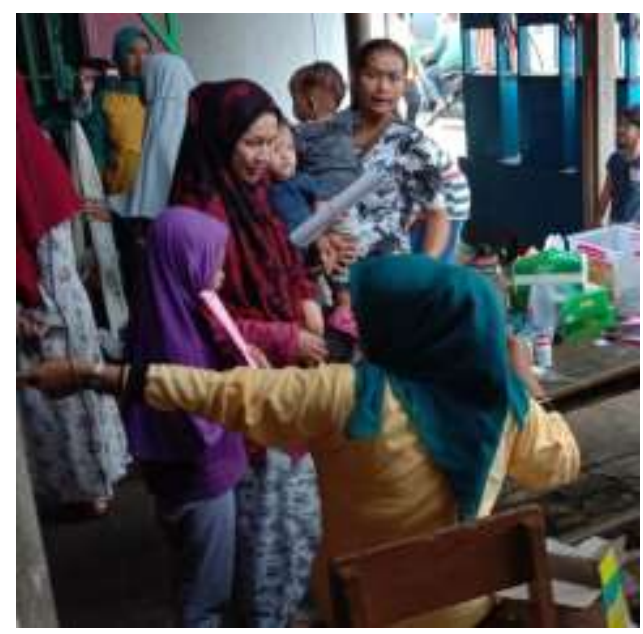

Sumber: Dokumentasi primer, 2020

Adanya peningkatan pengetahuan yang bermakna ini diharapkan dapat diikuti dengan perilaku pencegahan terhadap diabetes mellitus di masyarakat RW 01 Kelurahan Benda Baru. Hasil ini sejalan dengan pengabdian masyarakat mengenai diabetes mellitus pada masyarakat yang menunjukkan bahwa ada peningkatan pengetahuan secara bermakna mengenai diabetes mellitus (Khasanah U, et al, 2019).

Gambar 2. Kegiatan Pretest Post Test Di Posyandu RW 01 Kelurahan Benda Baru

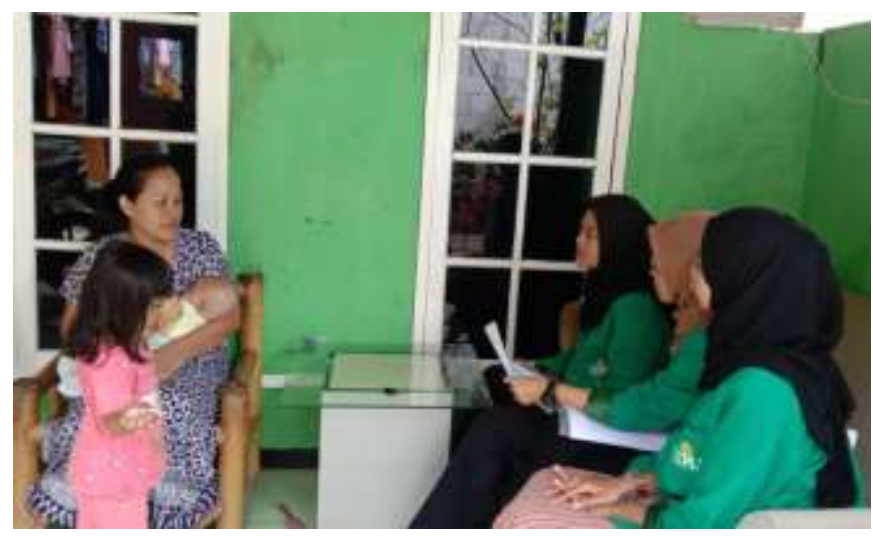

Sumber: Dokumentasi primer, 2020 
Gambar 3. Poster Pencegahan Penyakit Tuberkulosis

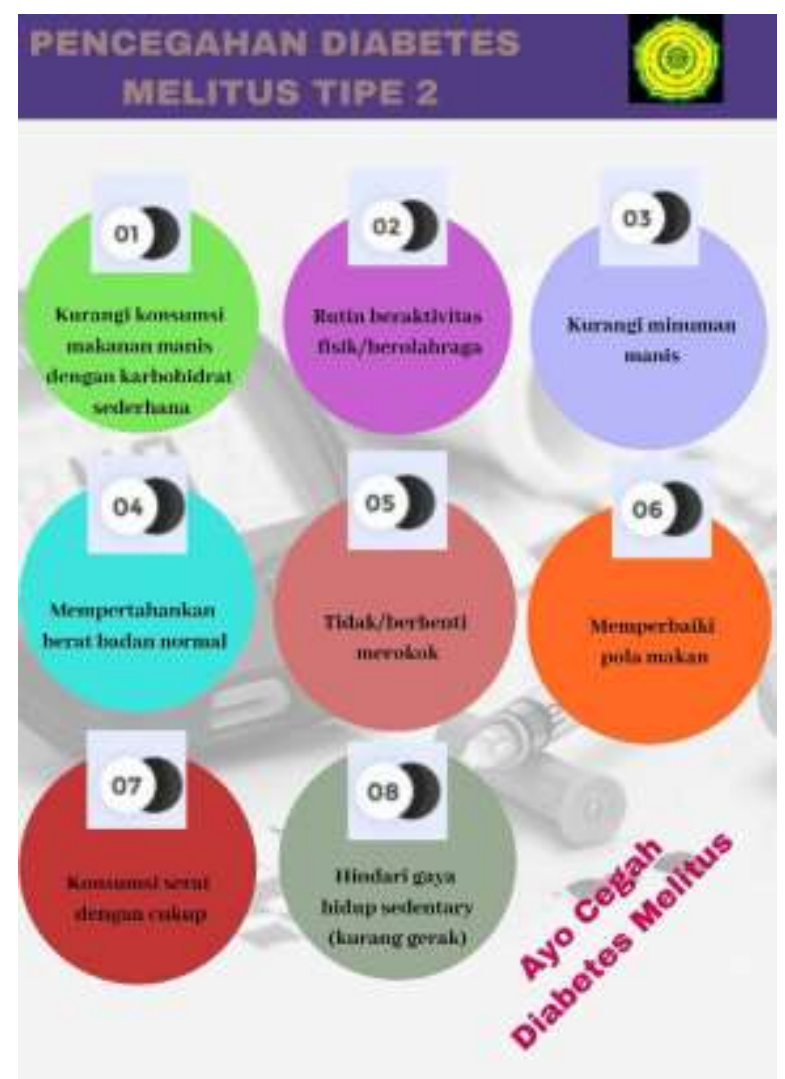

Sumber: Dokumentasi Primer, 2020

Penyuluhan kesehatan diberikan kepada ibu-ibu peserta posyandu karena ibu-ibu menjadi penyambung pesan bagi anggota keluarga lainnya dan akan menyampaikan pesan kepada sesama ibu dilingkungannya yang tidak berkesempatan hadir dalam kegiatan posyandu. Perempuan lebih berisiko mengidap diabetes mellitus akibat proses hormonal. Perubahan hormonal terkait siklus bulanan (premenstrual syndrome) dan pascamenopause menyebabkan perempuan berpeluang memiliki indeks masa tubuh yang lebih besar karena distribusi lemak tubuh yang mudah terakumulasi. Hal tersebut menyebabkan perempuan berisiko mendapatkan diabetes mellitus (Trisnawati,2013).

Perlu dilakukan upaya-upaya pencegahan diabetes mellitus mengingat komplikasinya dengan berbagai penyakit lain seperti kegagalan ginjal. Komplikasi diabetes mellitus dengan penyakit lain meningkatkan pembiayaaan kesehatan di rumah tangga. Ibu rumah tangga yang mempraktekkan pencegahan diabetes mellitus diharapkan dapat hidup sehat bebas diabetes dan berpotensi mengurangi pengeluaran perawatan kesehatan secara keseluruhan.

\section{KESIMPULAN DAN SARAN}

Setelah pemberian poster dan penyuluhan didapatkan peningkatan pengetahuan yang bermakna antara sebelum dan sesudah penyuluhan kesehatan pencegahan penyakit diabetes mellitus pada ibu-ibu peserta posyandu RW 01. Saran kepada Posyandu RW 01 agar rutin melakukan promosi kesehatan mengenai penyakit tidak menular khususnya diabetes mellitus kepada ibu-ibu RW 01. 


\section{UCAPAN TERIMA KASIH}

Terima kasih yang sebesar-besarnya kepada jajaran Puskesmas Benda Baru, Kelurahan Benda Baru, dan Kader Posyandu RW 01 yang telah memberikan waktu dan tempat untuk melakukan pengabdian Masyarakat ini. Semoga dapat bermanfaat dalam membantu pelaksanaan program pencegahan penyakit tidak menular di masyarakat RW 01.

\section{DAFTAR PUSTAKA}

Wu Y, Ding Y, Tanaka Y, Zhang W. 2014. Risk factors contributing to type 2 diabetes and recent advances in the treatment and prevention. Int $\mathrm{J}$ Med Sci [Internet]. Ivyspring International Publisher; 2014 [cited 2019 Mar 12];11(11):1185-200. Available from: http://www.ncbi.nlm.nih.gov/pubmed/25249787

Mahant SD, Kolay SK. 2014. Type 2 Diabetes; Affecting Factor \&amp; Prevalence among Mining Workers: A Case Study of NMDC Bacheli, Dantewada (Chhattisgarh). IOSR J Humanit Soc Sci (IOSR-JHSS [Internet]. 2015 [cited 2019 Mar 12];20(1):55-8. Available from: www.iosrjournals.org

IDF. IDF Diabetes Atlas power point [Internet]. 2017. [cited 2019 Jun 26]. Available from: https://diabetesatlas.org/

Kemenkes RI. 2019. Hari Diabetes Sedunia Tahun 2018. [Internet]. 2019[cited 2020 Apr 28]; Availablefrom:https://pusdatin.kemkes.go.id/download.php?file=download/pusdatin/in fodatin/infodatin-Diabetes-2018.pdf

Khasanah U, et al. 2019. Edukasi Masyarakat Dalam Peningkatan Pencegahan Dan Perawatan Hipertensi dan DM Desa Kaliasin Kecamatan Sukamulya Kabupaten Tangerang. Prosiding Seminar Nasional Pengabdian Masyarakat LPPM UMJ. E-Issn: 2714-6286. Website: Http://Jurnal.Umj.Ac.Id/Index.Php/Semnaskat

Trisnawati, Shara Kurnia dan Soedijono Setyorogo. 2013. "Faktor Risiko Kejadian Diabetes Melitus Type II di Puskesmas Kecamatan Cengkareng Jakarta Barat Tahun 2013”, Jurnal Ilmiah Kesehatan, Vol.5, No.1 